\title{
Magnetotelluric and temperature monitoring after the 2011 sub-Plinian eruptions of Shinmoe-dake volcano
}

\author{
Koki Aizawa ${ }^{1 *}$, Takao Koyama ${ }^{1}$, Makoto Uyeshima ${ }^{1}$, Hideaki Hase ${ }^{1,2}$, Takeshi Hashimoto ${ }^{3}$, Wataru Kanda ${ }^{2}$, \\ Ryokei Yoshimura ${ }^{4}$, Mitsuru Utsugi ${ }^{5}$, Yasuo Ogawa ${ }^{2}$, and Ken'ichi Yamazaki ${ }^{4}$ \\ ${ }^{1}$ Earthquake Research Institute, University of Tokyo, Yayoi 1-1-1, Bunkyo-ku, Tokyo 113-0032, Japan \\ ${ }^{2}$ Volcanic Fluid Research Center, Tokyo Institute of Technology, Ookayama 2-12-2, Meguro-ku, Tokyo 152-8551, Japan \\ ${ }^{3}$ Institute of Seismology and Volcanology, Faculty of Science, Hokkaido University, \\ N10W8, Kita-ku, Sapporo, Hokkaido 060-0810, Japan \\ ${ }^{4}$ Disaster Prevention Research Institute, Kyoto University, Gokasho, Uji, Kyoto 611-0011, Japan \\ ${ }^{5}$ Aso Volcanological Laboratory, Institute for Geothermal Sciences, Graduate School of Science, \\ Kyoto University, Minami-Aso, Kumamoto 869-1404, Japan
}

(Received November 1, 2012; Revised April 18, 2013; Accepted May 17, 2013; Online published July 8, 2013)

\begin{abstract}
Three sub-Plinian eruptions took place on 26-27 January 2011 at Shinmoe-dake volcano in the Kirishima volcanic group, Japan. During this event, GPS and tiltmeters detected syn-eruptive ground subsidence approximately $7 \mathrm{~km}$ to the WNW of the volcano. Starting in March 2011, we conducted broad-band magnetotelluric (MT) measurements at a site located $5 \mathrm{~km} \mathrm{NNW}$ of the volcano, beneath which the Shinmoe-dake magma plumbing system may exist. In addition, temperature monitoring of fumaroles and hot-springs near the MT site was initiated in July 2011. Our MT data record changes in apparent resistivity of approximately $\pm 5 \%$, along with a $\pm 1^{\circ}$ phase change in the off-diagonal component of the impedance tensor $\left(Z_{x y}\right.$ and $\left.Z_{y x}\right)$. Using 1-D inversion, we infer that these slight changes in resistivity took place at relatively shallow depths of only a few hundred meters, at the transition between a near-surface resistive layer and an underlying conductive layer. Resistivity changes observed since March 2012 are correlated with the observed temperature increases around the MT monitoring site. These observations suggest the existence beneath the MT site of pathways which enable volatile escape.
\end{abstract}

Key words: Magnetotellurics, temperature monitoring, resistivity monitoring, structural change.

\section{Introduction}

The Kirishima volcanic group, situated at the southern end of Kyushu Island, Japan, consists of more than 20 Quaternary volcanic cones that occur in a $\sim 20 \times 20 \mathrm{~km}$ area (Fig. 1). Historical eruptions have occurred at three volcanoes from this group: Iwo-Yama, Ohachi, and Shinmoedake. Since the 1923 eruption of the Ohachi volcano, all other eruptions (i.e., the 1959, 1962, 1991, 2010, and 2011 eruptions) occurred at Shinmoe-dake volcano, with the 2011 eruptions being the largest on record over the past 290 years (i.e., since a similar-scale eruption in 1717). The 2011 event started with a series of small eruptions on 19 and 22 January, followed by three sub-Plinian eruptions on 26-27 January and the subsequent emergence of lava within the crater. Synchronous with these events, global positioning system (GPS) instruments and tiltmeters detected significant ground subsidence in an area approximately $7 \mathrm{~km}$ WNW of Shinmoe-dake (Fig. 1), at an estimated source

*Now at Institute of Seismology and Volcanology, Faculty of Sciences, Kyushu University, 2-5643-29 Shin'yama, Shimabara, Nagasaki 855-0843, Japan.

Copyright (C) The Society of Geomagnetism and Earth, Planetary and Space Sciences (SGEPSS); The Seismological Society of Japan; The Volcanological Society of Japan; The Geodetic Society of Japan; The Japanese Society for Planetary Sciences; TERRAPUB.

doi:10.5047/eps.2013.05.008 depth of $\sim 10 \mathrm{~km}$ (Nakao et al., 2011; Ueda et al., 2013; Kozono et al., 2013). The estimated volume of this deflation is consistent (within one order of magnitude) with the erupted dense rock equivalent $\left(0.021-0.027 \mathrm{~km}^{3}\right.$; Nakada et al., 2013). These observations suggest that a magma chamber exists approximately $7 \mathrm{~km}$ WNW of Shinmoedake volcano, connected by a subsurface plumbing system to the Shinmoe-dake crater prior to the 2011 eruptions. In February 2011, the style of eruption of this volcano has switched from sub-Plinian to Vulcanian, during which a $400-\mathrm{kg}$ volcanic bomb was ejected as far as $3.2 \mathrm{~km}$ from the vent. Due to the dangerous nature of these eruptions, people were prohibited from entering within a $4-\mathrm{km}$ radius of the Shinmoe-dake crater. This eruptive activity then gradually subsided, and the latest eruption as of this writing (on 7 September 2011) comprised only an ash emission. After the sub-Plinian eruptions, GPS instruments initially detected a continuous inflation event occurring at approximately the same location as the previously documented syn-eruptive deflation event, although this late-stage inflation has subsequently ceased in late 2011 (Nakao et al., 2012).

Pre-eruptive activity also occurred. For example, GPS data indicate that ground inflation had commenced as early as February 2010 (Nakao et al., 2011). The source of these pre- and post-eruptive inflations is identical to the source region of the syn-eruptive deflation $(7 \mathrm{~km}$ WNW of Shinmoedake and at a depth of $10 \mathrm{~km}$ ). However, no significant 


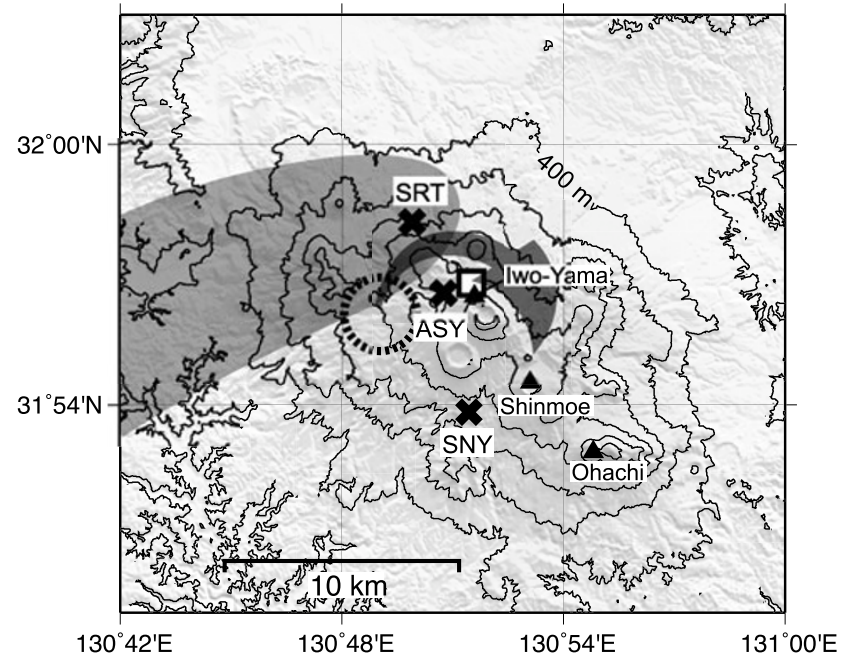

Fig. 1. The MT monitoring site at Kirishima volcanic group. The topographic contour interval is $200 \mathrm{~m}$. The square shows the location of the MT site, some $400 \mathrm{~m}$ north of Iwo-Yama volcano; crosses with name labels (SRT, ASY, and SNY) indicate the location of temperature measurement sites, and the dashed circle indicates the possible location of the deformation source (Nakao et al., 2011; Ueda et al., 2013; Kozono et al., 2013). The dark shaded area and the arrow indicate the possible location of a deep conductive body and inferred magma movements during the 2011 Shinmoe-dake eruptions, respectively (Aizawa et al., submitted).

seismic activity or ground deformation occurred between 22 and 26 January, meaning that the timing, magnitude, and location of the three sub-Plinian eruptions on 26-27 January was almost entirely unexpected. Only studies carried out on the erupted material itself suggested the possibility of any impending large magmatic eruptions. In particular, Suzuki et al. (2013) analyzed the volcanic ash erupted on 19 January, and found that it contains $8 \%$ juvenile micro-pumice in particle number, which indicates that magma must have reached at a relatively shallow level beneath the Shinmoedake crater at that time. On the days of the sub-Plinian eruptions, subtle changes in strain were detected several hours prior to each eruption by a vault-housed extensometer deployed approximately $18 \mathrm{~km} \mathrm{NW}$ of the Shinmoe-dake crater (Yamazaki et al., submitted).

To understand the current state of Shinmoe-dake volcano and to forecast the next large-scale magmatic eruption, we deployed a number of scientific instruments at distances of 3-10 km from this volcano (Fig. 1) to monitor and measure changes in temperature, and at one station (situated 5 $\mathrm{km}$ away) installed equipment to measure electrical resistivity. In this paper, we present the results of that monitoring study, and report on observed temporal variations in electrical resistivity and temperature that occurred after the 2011 sub-Plinian eruptions. Although the imaging of subsurface magma transport is usually quite difficult due to the relatively small volumes of magma involved, some previous seismic studies have indicated that abundant (and observable) structural changes are common in the rocks surrounding the magma conduit. A number of different causes for these structural changes have been proposed, including changes in local stress fields, crack opening/fracture propagation, and/or volatile degassing (Miller and Savage, 2001;
Patane et al., 2006; Brenguier et al., 2008).

\section{Methods of Observation and Instrumental Setup}

\subsection{Magnetotelluric monitoring}

The magnetotelluric (MT) method uses the natural electromagnetic field variation to image subsurface resistivity structure, and usually involves measuring two horizontal electric field components $\left(E_{x}\right.$ and $\left.E_{y}\right)$ and three magnetic field components $\left(B_{x}, B_{y}\right.$, and $\left.B_{z}\right)$ at the Earth's surface, where the subscripts $x$ and $y$ indicate the N-S and E-W directions, respectively. From time series data, the impedance tensor $Z$ and geomagnetic transfer functions $T$ are calculated in the frequency domain as

$$
\left(\begin{array}{c}
E_{x}(f) \\
E_{y}(f)
\end{array}\right)=\left(\begin{array}{ll}
Z_{x x}(f) & Z_{x y}(f) \\
Z_{y x}(f) & Z_{y y}(f)
\end{array}\right)\left(\begin{array}{l}
B_{x}(f) \\
B_{y}(f)
\end{array}\right),
$$

and

$$
B_{z}(f)=\left(\begin{array}{ll}
T_{x}(f) & T_{y}(f)
\end{array}\right)\left(\begin{array}{l}
B_{x}(f) \\
B_{y}(f)
\end{array}\right) .
$$

$B_{z}$ is the geomagnetic field in the vertical direction. Impedance tensors and geomagnetic transfer functions are complex numbers to calculate mathematically and are generally referred to as MT response functions. Each component of the impedance tensor is usually expressed as an apparent resistivity $\rho_{\mathrm{a}}(\mathrm{ohm}-\mathrm{m})$ and phase $\phi$ (degree), as follows:

$$
\rho_{\mathrm{a} i j}(f)=\frac{1}{5 f}\left|Z_{i j}(f)\right|^{2}
$$

and

$$
\phi_{i j}(f)=\arctan \left[\frac{\operatorname{Imaginary}\left(Z_{i j}(f)\right)}{\operatorname{Real}\left(Z_{i j}(f)\right)}\right],
$$

where $i, j$ denotes either $x$ or $y$. The impedances $\left(Z_{i j}\right)$ in Eqs. (3) and (4) are based on units of $\mathrm{mV} / \mathrm{km}$ and $\mathrm{nT}$, respectively. In the case of homogeneous half-space, $Z_{x x}$ and $Z_{y y}=0, Z_{x y}=Z_{y x}$, and the apparent resistivity is equal to resistivity in the ground.

Using the real part of the geomagnetic transfer function, the induction vector is graphically represented in the $x y$ plane as

$$
\left(-\operatorname{Real}\left(T_{x}(f)\right), \quad-\operatorname{Real}\left(T_{y}(f)\right)\right)
$$

This representation is frequently used to evaluate the dimensionality (D) of the subsurface resistivity structure, because it tends to point to the relatively conductive material in the vicinity of the measurement site. In the 1-D case (the resistivity changes only in the vertical direction) the induction vector becomes $(0,0)$.

The MT method is useful for investigating static resistivity structures and temporal variations in these structures; however, in practice, this technique is mainly used to investigate static structures. The resistivity structure is deduced by the inversion of impedances and/or geomagnetic transfer functions. The higher-frequency data correspond to shallower resistivity structure, whereas the lowerfrequency data correspond to deeper resistivity structure. 
Because the MT method can be used to conduct deep (a few hundred kilometers) sounding without preparing an artificial electric source, this method has been widely applied in studies aimed at imaging the various scales of resistivity structure. In particular, we have already used the MT method to evaluate the large-scale subsurface resistivity structure present within the seismogenic zone beneath the Japanese Archipelago Island Arc system (Ogawa et al., 2001; Uyeshima et al., 2005; Yoshimura et al., 2009), and to evaluate the smaller-scale (shallow) resistivity structure beneath a number of historically active Japanese volcanoes (Ogawa et al., 1998; Hase et al., 2005; Aizawa et al., 2009b; Kanda et al., 2010).

MT monitoring studies are relatively underused compared with the other techniques that can be employed to survey resistivity structures. Resistivity monitoring generally involves the measuring of DC electric currents, as undertaken near the active craters of Izu-Oshima and Miyakejima volcanoes, Japan (Yukutake et al., 1990; Utada, 2003; Zlotnicki et al., 2003). More recent long-term MT monitoring has been used to determine whether precursory resistivity changes occur prior to earthquakes in the area around $\mathrm{Ru}-$ apehu volcano (Hanekop and Simpson, 2006), and in California (Kappler et al., 2010). MT methods have also been used to monitor fluid movements beneath Sakurajima volcano in Japan (Aizawa et al., 2011) and during geothermal exploration in Australia (Peacock et al., 2012).

In the present study, an MT monitoring site was established $5 \mathrm{~km}$ NNW of the Shinmoe-dake crater in March of 2011 (Fig. 1). This site is located $400 \mathrm{~m} \mathrm{NE}$ of the IwoYama volcano, which has a historical record of phreatic eruptions. Prior to 1990, a fumarolic area spanning about $500 \times 500 \mathrm{~m}$ also developed on Iwo-Yama, although there is currently no fumarolic activity near this volcano. At the MT site, geomagnetic fields $\left(B_{x}, B_{y}\right.$, and $\left.B_{z}\right)$ and Earth currents $\left(E_{x}\right.$ and $\left.E_{y}\right)$ were recorded using a Metronix ADU07 system. The sampling frequencies were $32 \mathrm{~Hz}$ (00:00-23:50 UT) and $1024 \mathrm{~Hz}$ (17:00-19:00 UT). Non-polarized Pb$\mathrm{PbCl}_{2}$ electrodes were placed at intervals of $40 \mathrm{~m}$ in the $\mathrm{N}-\mathrm{S}$ direction and $35 \mathrm{~m}$ in the $\mathrm{E}-\mathrm{W}$ direction. The contact resistance between the soil and a given electrode was maintained at $<6,000 \mathrm{ohm}-\mathrm{m}$, but $E_{y}$ channel values drifted to $>10,000 \mathrm{ohm}-\mathrm{m}$ up to December 2011. This drift resulted in drifting of impedance phases to around $80-320 \mathrm{~Hz}$; these values were corrected immediately by changing electrodes in December 2011, and the apparent resistivity across all frequency ranges was not influenced by this changing of electrodes. The electrical power supply was maintained by a series of solar panels ( $80 \mathrm{~W}$ each $\times$ six panels), a charging controller, and a number of deep-cycle batteries (105 Ah each $\times$ six batteries). Approximately every two months, we visited the MT observation site to maintain the MT apparatus, replacing the electrodes if necessary and collecting the digital time series data that had been recorded.

\subsection{Temperature monitoring}

For temperature monitoring in this study, the thermistor sensors and data loggers (TandD TR-5420 and TR-52i, respectively) were deployed at the surface of three separate geothermal zones (labeled SRT, ASY, and SNY in Fig. 1), and the temperature measurements commenced in
June 2011. The temperature resolution of the data logger is $0.1^{\circ} \mathrm{C}$. Measurement site SRT (Shiratori Jigoku) is situated at an altitude of $820 \mathrm{~m}$, where numerous hightemperature fumaroles and boiling hot-springs exist in an area measuring approximately $200 \times 200 \mathrm{~m}$. At this site, the sensor was set into one of the open holes, which was observed to spout out vapor with a hissing sound. Measurement site ASY (Ebino-kogen Asiyu) is situated at an altitude of $1190 \mathrm{~m}$, and is within $1.3 \mathrm{~km}$ of the MT monitoring site and Iwo-Yama volcano. At this hydrothermally active site, low-temperature hot-spring water is drawn up from a depth of $60 \mathrm{~m}$, and then used as a footbath for tourists; the ASY site represents an unconfined rather than an artesian well. At a distance of $30 \mathrm{~m}$ from this footbath, there exists a small outpouring of hot-spring water and gas bubbles at the surface due to fracturing of the casing pipe, and it is within this surface outpouring that the temperature monitoring sensor was placed at the ASY site. Site SNY (Shinyu) is located at an altitude of $920 \mathrm{~m}$, at a place where a broad $(300 \times 300 \mathrm{~m})$ zone of fumarolic and hot-spring activity exists. At this site, the sensor was inserted into one of the fumaroles. All temperature monitoring data in this study were recorded every 10 minutes. During our excursions to the MT site about once every two months, we also visited these three temperature-monitoring sites to maintain the apparatus and to collect the digital time series data that had been recorded.

\section{Data}

\subsection{MT response function}

Although there are no electrical power lines near the MT monitoring site, artificial $60-\mathrm{Hz}$ noise (and associated odd-order overtones at 180, 300, and $420 \mathrm{~Hz}$ ) originating from distant commercial power lines is still observed in the recorded power spectra of all five measured components $\left(E_{x}, E_{y}, B_{x}, B_{y}\right.$, and $\left.B_{z}\right)$. Due to these different frequency noises, the quality of the MT response functions is not good in frequency ranges of $>60 \mathrm{~Hz}$. To reduce these noises, we applied a notch filter to the time series. A Fourier transform was applied to the raw data, the result of which was then transformed to a frequency domain. In this step, the amplitudes of the $60 \mathrm{~Hz}$ odd-order overtones were reduced to $1 / 100$ of their initial values, with a notch width of 0.1 Hz. Finally, the time series data were recovered by applying an inverse Fourier transform. By applying this comblike notch filter, the quality of MT response functions was significantly improved, especially at frequencies near $60 \mathrm{~Hz}$ and at odd-order overtones.

The MT response functions in this study are calculated using the robust estimation code (Chave and Thomson, 2004). At high frequencies (above $0.1 \mathrm{~Hz}$ ), we also employed remote-reference processing (Gamble et al., 1979) using MT data recorded at Sakurajima volcano $(50 \mathrm{~km}$ south of Kirishima), where an identical apparatus measures the MT data at that location, based on the same time schedule as our MT apparatus. In the low-frequency range below $0.1 \mathrm{~Hz}$, the geomagnetic data recorded at the Kakioka Geomagnetic Observatory of Japan Meteorological Agency (located $1000 \mathrm{~km}$ ENE of Kirishima) were used for remotereference processing, primarily as the lower-frequency data 


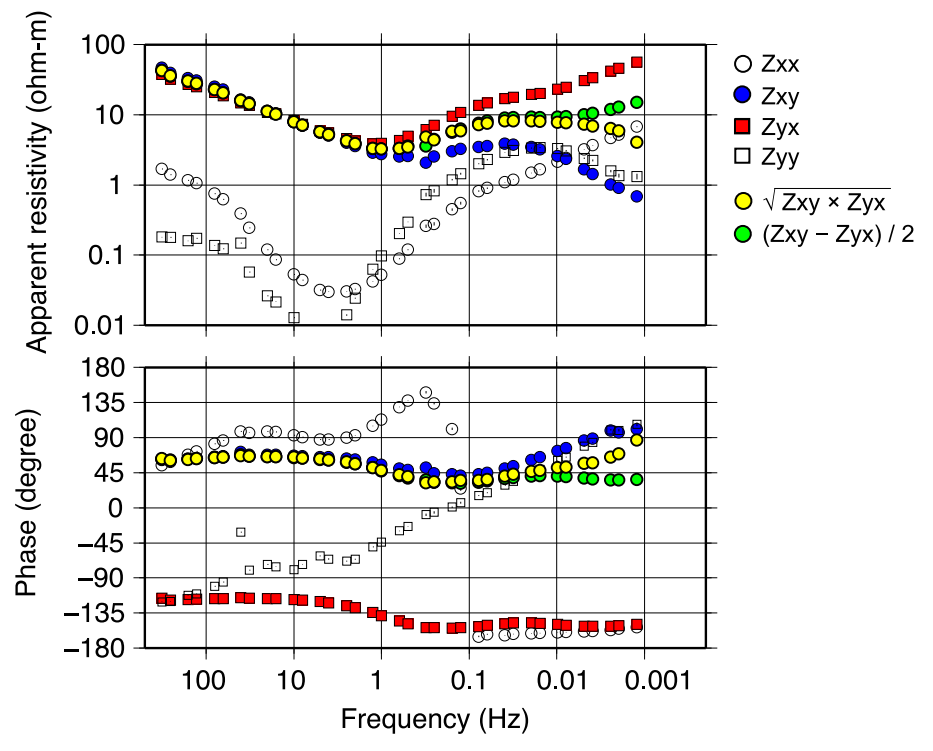

Fig. 2. Sounding curves of the MT monitoring site. In the calculation, all data for the observation period are used. Errors, which are shown vertical bars, are smaller than symbols.

obtained at proximal stations were of poorer quality than the data obtained at the magnetic observatory. Using these procedures, we obtained the daily MT response functions across a broad frequency range of 320-0.001 Hz.

Figure 2 shows the resultant sounding curves for the MT monitoring site, obtained by stacking the daily impedances, as shown in Fig. 3. The lowest-quality $10 \%$ of the data, as defined using the size of error bars on the data, was removed to improve interpretation quality; only the remaining $90 \%$ higher-quality data were stacked. Uncertainties within the stacked data were evaluated by an error propagation equation by assuming that the errors in the daily impedance were independent. At frequencies above $1 \mathrm{~Hz}$, the apparent resistivity of $Z_{x y}$ is approximately the same as that of $Z_{y x}$, but these values gradually diverge from one another as frequencies decrease progressively below $1 \mathrm{~Hz}$. The apparent resistivities of $Z_{x x}$ and $Z_{y y}$ are minor in comparison with the apparent resistivities of $Z_{x y}$ and $Z_{y x}$, except at lower frequencies where these values converge with those for $Z_{x y}$ and $Z_{y x}$. These results indicate that the overall resistivity structure can be approximated as 1-D at shallow regions beneath the MT site, but gradually shows 3-D features at deeper levels. The mean values of off-diagonal components (yellow and green circles in Fig. 2) are discussed in Section 4.

Figure 3 shows two representative examples (i.e., for the off-diagonal components $Z_{x y}$ and $Z_{y x}$ ) of the observed temporal variations of apparent resistivity and phase measurements at the MT site, each of which displays five selected (i.e., representative) subsets of data that were measured at specific frequencies of $20,1.25,0.16,0.04$, and $0.01 \mathrm{~Hz}$. The data for the diagonal components $\left(Z_{x x}\right.$ and $\left.Z_{y y}\right)$ are not shown in Fig. 3 because their amplitudes are (for the most part) minor in comparison with those for the off-diagonal data (see Fig. 2), but also because these data-points have relatively large associated error bars. It is clear from Fig. 3 that the quality of the impedance data is better for the higherfrequency datasets than for the lower, and this is because the cumulative number of stacked responses increases with increasing frequency. The poorest-quality data corresponds to about $0.16 \mathrm{~Hz}$, which is known as a dead band where natural electromagnetic signals are relatively weak. Figure 3 also shows that the measurement of $Z_{x y}$ data was poorly conducted in October-December 2011 and in March 2012 due to electrode problems. Neglecting the small-scale (i.e., short-duration) fluctuations in the data, we observe no major changes in apparent resistivity or phase measurements throughout the entire duration of our MT monitoring study. These remarkably stable impedances indicate that the overall resistivity structure beneath the MT site remained stationary throughout this period. However, upon closer inspection, the 20 and $1.25 \mathrm{~Hz}$ data show small progressive changes in apparent resistivity and phase measurement.

Figure 4 shows a representative example of the temporal variations of amplitude and orientation observed for the induction vector. These results show that throughout the observation period, these amplitudes remained small and stable, which indicates that the resistivity structure beneath the MT site can be approximated as a first-order 1-D structure during this entire interval of time. We note, however, that in the data from December 2011, the $20 \mathrm{~Hz}$ data show a small step-like variation, but the absolute cause or significance of this pattern is unclear.

\subsection{Temperature}

Figure 5 shows the temporal evolution of the temperature data collected during our monitoring study, with each data-point representing a single 1-day average. For comparison, precipitation data and eruption activity for the region are also shown. At the SRT and SNY sites, the instrument sensors were not perfectly inserted into the open fumarole holes from July to November 2011, resulting in a high degree of fluctuation in these data. These sensors were adjusted, placed in a more secure location within the fumarole hole, and rocks were placed to fix the sensor cable on 30 November 2011.

It is clear that increased rainfall leads to an instantaneous 



Fig. 3. Temporal changes of daily apparent resistivity (left) and phase (right) of off-diagonal components of impedance tensor $\left(Z_{x y}\right.$, and $\left.Z_{y x}\right)$. The error bars are double sided 95 per cent jackknife confidence limits (Chave and Thomson, 2004). Data in the five frequencies (20, 1.25, 0.16, 0.04, and 0.01) are shown.

decrease in recorded temperature, based on correlations of daily trends in precipitation and raw temperature data (not shown). However, the one-day time-averaged data in Fig. 5 reveal that the long-term temperature trends actually remain quite stable against a few days of rainfall. For example, the temperature decrease linked with typhoon rainfall in September 2011 soon recovered several days later. The temporal variations in temperature recorded in this study also show significant contrasts between fumarole versus hot-spring settings, whereby the high-temperature fumarole data (sites SRT and SNY) show relatively punctuated fluctuations, while the low-temperature hot-spring data (site ASY) show more gradual variations.

\section{Analysis}

\subsection{1-D inversion of the MT data}

Images of subsurface resistivity structure are estimated by the inversion of MT response functions, and in the present case (i.e., deployment of a single MT site), 1-D inversion is the most practical approach. Therefore, in this study we used the $>0.01 \mathrm{~Hz}$ apparent resistivity data (and corresponding phase data) to generate a first-order, 1-D approximation of the subsurface resistivity structure beneath the MT site. The data at frequencies below $0.01 \mathrm{~Hz}$ were excluded from the inversion because the apparent resistivity of the diagonal component exceeds that of $Z_{x y}$ and shows 3-D features; in addition, geomagnetic transfer functions were not used in the inversion due to the assumption of 1-D 


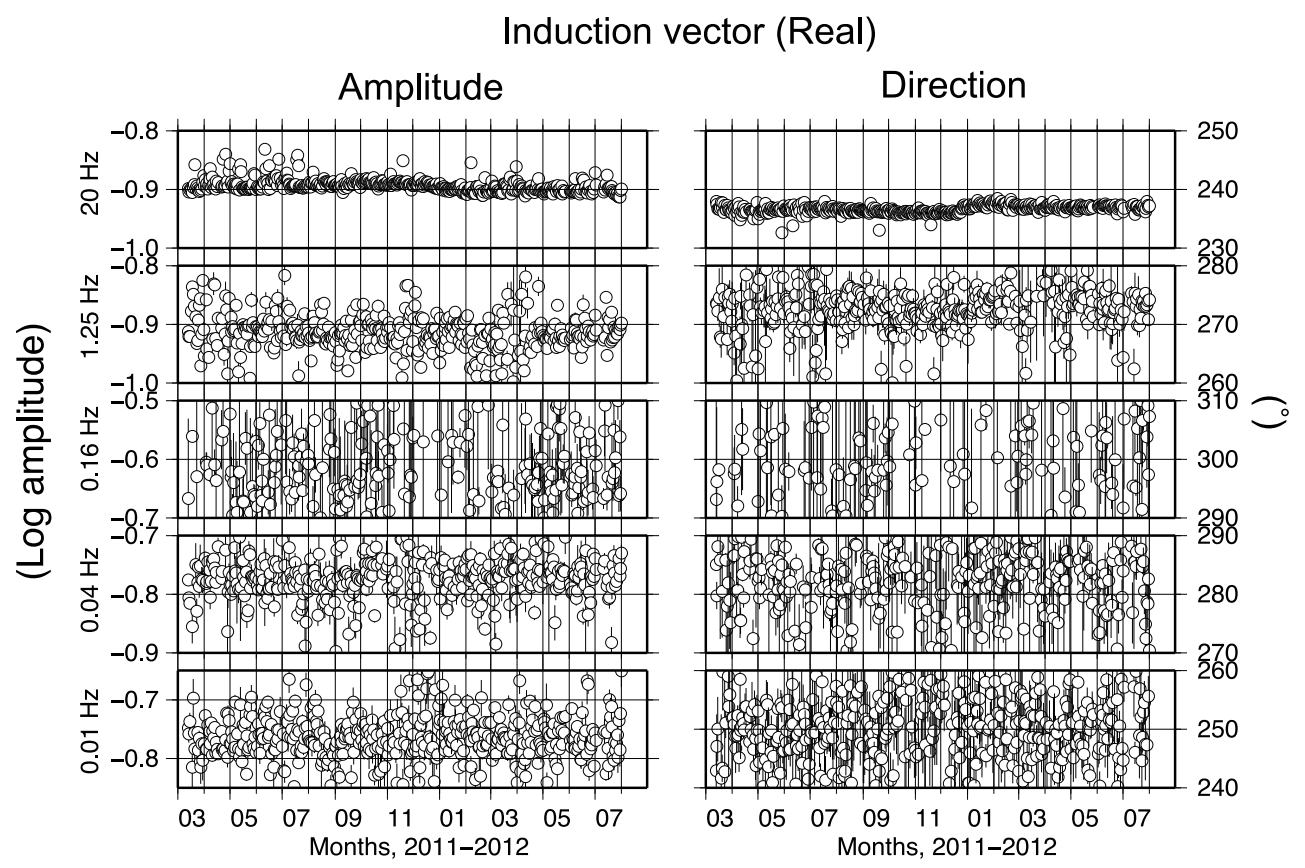

Fig. 4. Time change of induction vector (real part). Directions are based on Parkinson criteria, and are shown by counter clockwise from East.

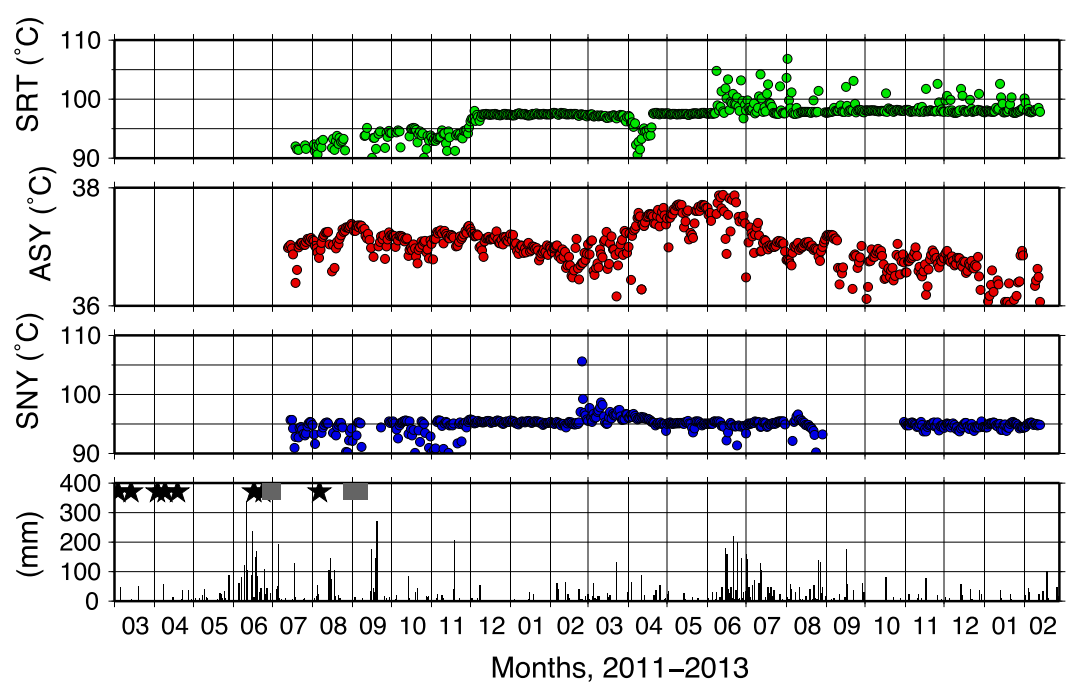

Fig. 5. Temperature variation at the monitoring sites. 1 day average values are shown. Sensor positions at SRT and SNY are moved $10 \mathrm{~cm}$ on November 30, 2011. For comparison, daily precipitation recorded at a site located $1 \mathrm{~km}$ west of ASY is shown at the bottom panel. Stars and grey rectangles show eruptions and continuous ash emission of Shinmoe-dake volcano, respectively.

structure.

The apparent resistivity and phase values were calculated from the arithmetic average $\left(Z_{x y}-Z_{y x}\right) / 2$, and then used as input for the 1-D inversion. Although the determinant $\left(\sqrt{Z_{x x} * Z_{y y}-Z_{x y} * Z_{y x}}\right)$ of the impedance tensor is also commonly used in this type of 1-D analysis, this approach was not used during this study, primarily as calculated values had significant scatter at frequencies of $<1 \mathrm{~Hz}$, due to relatively poor estimations of $Z_{x x}$ and $Z_{y y}$ values. It should be noted that there is no significant difference between the arithmetic average and determinant values at $<1 \mathrm{~Hz}$, primarily as $Z_{x x}$ and $Z_{y y}$ values are very small within this frequency range (Fig. 2). We also applied the Occam approach (Constable et al., 1987), which adapts the smoothest model according to the target root mean square (RMS) mis- fit, which is usually set at 1.0. The initial inversion model uses a half-space with a resistivity of $100 \mathrm{ohm}-\mathrm{m}$, and we used 16 frequencies in the inversion: $320,160,80,32,20$, $8,5,2.5,1.25,0.63,0.31,0.16,0.08,0.04,0.02$ and 0.01 Hz. We assigned error bars of $\pm 5 \%$ to each impedance value, which corresponds to \pm 0.0217 in log apparent resistivity and \pm 1.43 degree in phase, with the exception of the 8 and $20 \mathrm{~Hz}$ data (which were assigned smaller error bars of $\pm 2.5 \%$, as they approximately coincide with the $1 \mathrm{st}$ and $3 \mathrm{rd}$ harmonics of the Schumann resonance) and the $80-320 \mathrm{~Hz}$ phase data (which were assigned larger error bars of $\pm 20 \%$ due to increased contact resistance that sometimes caused the data to drift and fluctuate). Figure 6 shows the results of this 1-D inversion using the MT impedance data shown in Fig. 2. In this 1-D inversion, the final RMS approaches 

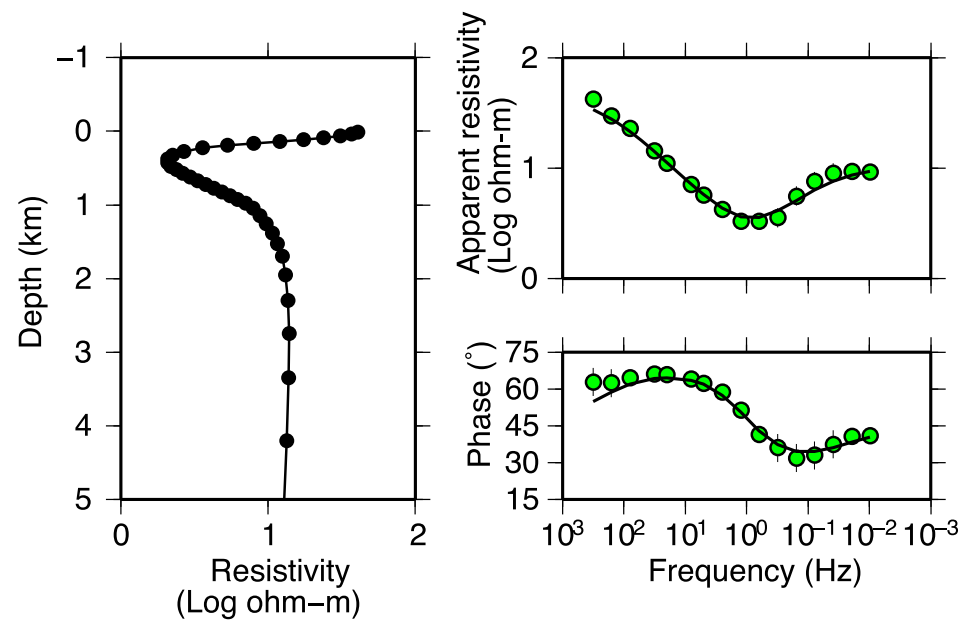

Fig. 6. An example of 1D inversion using the MT data shown in Fig. 2. The result can be regarded as a background structure during observational period. Right panel shows the fitness of the resistivity model. Green circle and solid line indicate data and theoretical response, respectively.

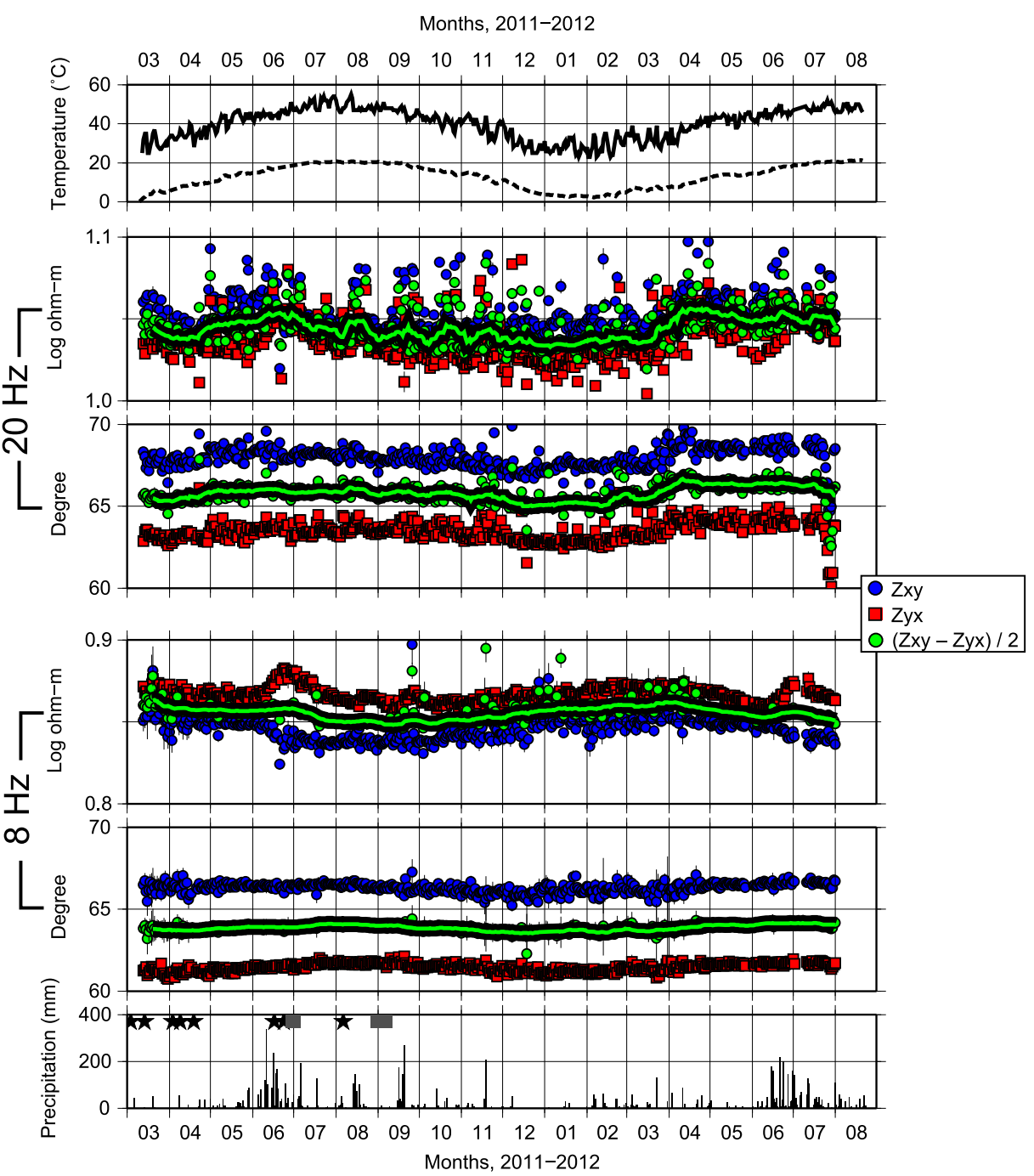

Fig. 7. Apparent resistivity and phase variations in the frequency of $20 \mathrm{~Hz}$ at the MT monitoring site. Thick green line indicates moving average with a time window of 2 weeks.

values of less than 1.0.

To elucidate temporal variations in resistivity structure, we attempted to invert the daily impedance. Figure 7 shows the variation in daily impedance at 8 and $20 \mathrm{~Hz}$ frequen- cies that correspond to the 1st and 3rd harmonics of the

Schumann resonance, respectively. Because there is significant scatter in the arithmetic averages of impedance, the results of the 1-D inversion are also scattered. To address 


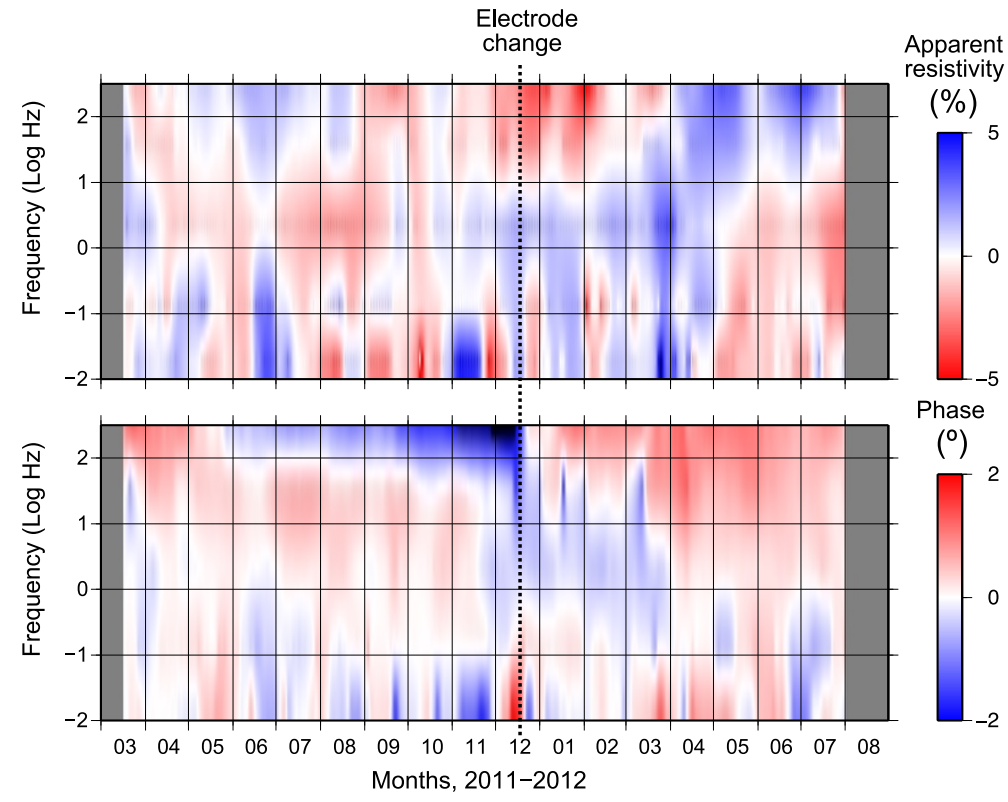

Fig. 8. Temporal variations in the smoothed apparent resistivity and phase shown in a color pseudo-section. For simplicity, only $\left(Z_{x y}-Z_{y x}\right) / 2$ is shown. Upper panel shows change in apparent resistivity $(\%)$ while the lower panel shows change in phase $\left({ }^{\circ}\right)$; both are deviations from the average values of each frequency. The phase jump in December 2011 at $80-320 \mathrm{~Hz}$ is due to a change in electrodes; a detailed explanation is provided in the main text.

(a)

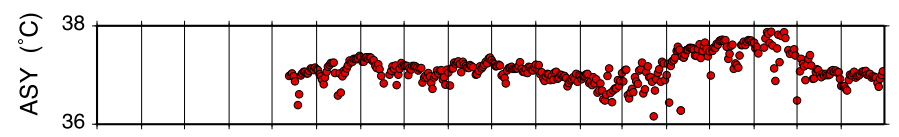

(b)

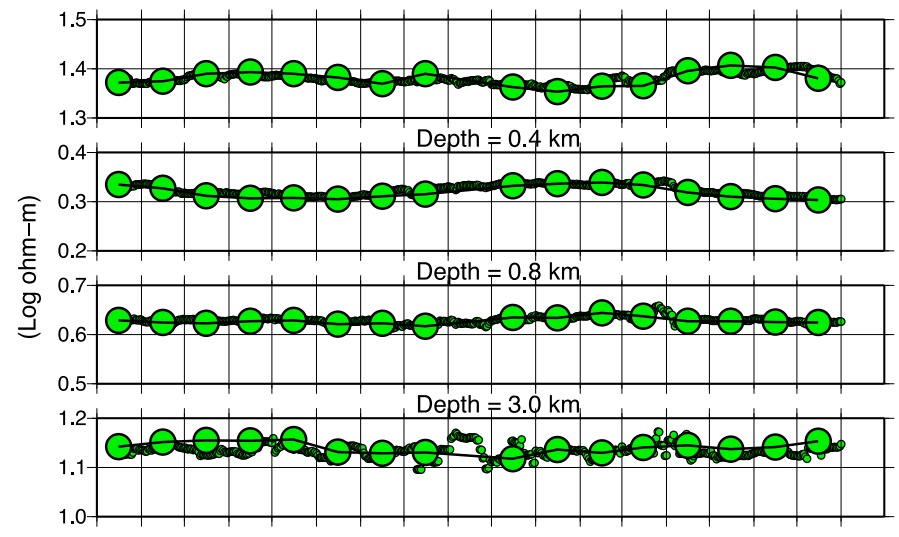

(c)

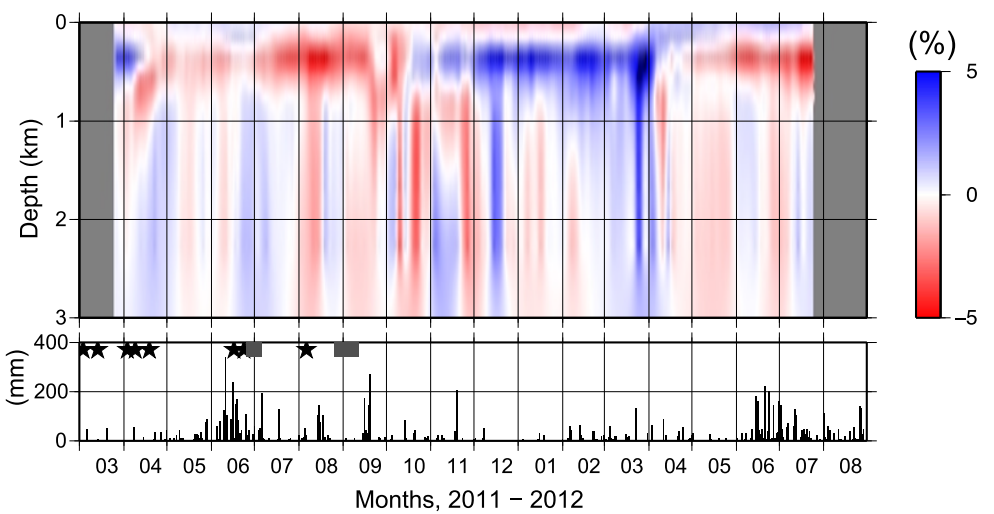

Fig. 9. Temporal changes in resistivity structure within the study area compared with variations in temperature and precipitation. (a) Temperature variation at the ASY site, $2 \mathrm{~km}$ WSW of the MT monitoring sites (Fig. 5). (b) Temporal change in the resistivity structure estimated using a 1D Occam inversion; small and large green circles indicate results derived from smoothed 1 day and 1 month average data, respectively. Note that scatter associated with the 1 month average for November 2011 was caused by electrode problems, resulting in unreliable data. (c) Resistivity changes monitored by percentage deviation from the average value for each depth. (d) Timing of precipitation and volcanic eruptions in the study area; the notation used is as in Figs. 5 and 7. 
this problem, we smoothed the data before carrying out the inversions, which first involved removing the outliers (beyond $\pm 10 \%$ ) from the stacked impedance data (Fig. 2) at each frequency. This procedure essentially requires the assumption that impedance does not show any real temporal variations beyond $\pm 10 \%$. It should be noted that the percentage of outliers varies from approximately $1 \%$ at higher frequencies to around $50 \%$ at the lower frequencies, and reaches up to $90 \%$ at dead band values around $0.16 \mathrm{~Hz}$. Second, a moving average with a time window of two weeks was applied to the daily impedance data. As a result, the smoothed data show approximately $\pm 5 \%$ apparent resistivity changes and $a \pm 1$ degree phase change. This two-step procedure was applied to all frequencies, resulting in significant smoothing of the data, but even with this screening method the data corresponding to the dead band $(0.31$, $0.16,0.08$, and $0.04 \mathrm{~Hz}$ ) were still scattered. Therefore, we assigned large error bars of $\pm 50 \%$ to these dead-band data. The variation in smoothed daily impedance across the entire range of frequencies is shown as a color pseudosection in Fig. 8; for simplicity, only $\left(Z_{x y}-Z_{y x}\right) / 2$ values are shown. The upper panel in this figure shows the change in apparent resistivity (in \%), and the lower panel shows phase changes (in degrees). As noted in Subsection 2.1, the contact resistance between the soil and one electrode drifted to values of over $10,000 \mathrm{ohm}-\mathrm{m}$; this drift in contact resistance was recovered by changing the electrodes in December 2011. Figure 8 shows that contact resistance has a significant phase effect at frequencies of $80-320 \mathrm{~Hz}$, although the apparent resistivity across these frequencies was much less influenced. In addition, an apparent resistivity pseudo-section shows a negative correlation between temporal variations at higher frequencies (above $10 \mathrm{~Hz}$ ) and lower frequencies (below $10 \mathrm{~Hz}$ ).

By using the smoothed impedances, we were able to compute a stable convergence of each inversion to a target RMS of 1.0. Figure 9 shows the observed temporal variation of 1-D resistivity structure estimated in this study. To allow for direct comparisons, the temperature variations at site ASY (1.3 km from the MT monitoring site), and precipitation data for the region are shown alongside these 1$\mathrm{D}$ resistivity structure data. Because 1-D inversion of the dead-band data is not plausible according to the two-step smoothing procedure outlined above, we also performed each inversion by using the data averaged over each onemonth period, from which we confirmed the similarity of both results. The estimated resistivity changes are approximately $\pm 5 \%$, and the polarity differs between depths of 100 and $400 \mathrm{~m}$ (Fig. 9).

4.2 Assessing the significance of MT impedance variations

The fact that observed impedance and inferred resistivity variations are quite small means that evaluation of the causes of the temporal changes in impedance and inferred resistivity needs to be carefully undertaken. An initial assessment suggests that rainfall is the most likely cause of the resistivity changes; for instance, the $8 \mathrm{~Hz}$ data shown in Fig. 7 clearly indicate that $Z_{x y}$ and $Z_{y x}$ apparent resistivity values diverged during the rainy season in June 2011 and 2012, although with no corresponding phase changes
(Fig. 7). These observations suggest that heavy and longterm rainfall caused local disturbances in surficial resistivity structures around the MT site with no corresponding temporal change in geomagnetic transfer functions (Fig. 4); these functions should theoretically not change during these sorts of local distortions. We also observe that rainfall-related impedance disturbances disappear when average impedance values are used (Fig. 7).

Aside from rainfall, the actual change in temperature itself may affect the output of the measurement system, resulting in artificial variations of MT response functions. In particular, it is known that the induction coils in our MT monitoring instruments are sensitive to changes in the temperature of their surrounding environment, because the permeability of the core material varies systematically with changes in temperature. In comparison, Fig. 7 also shows temporal surface temperature variations, both in the MT logger and at a depth of $30 \mathrm{~cm}$; note that the induction coils were installed at a depth of approximately $30 \mathrm{~cm}$. It is immediately apparent that both sets of temperature data exhibit the same overall seasonal variability of approximately $\pm 10^{\circ} \mathrm{C}$. Here, we know that the output reading from the induction coil can vary by a value of $0.09 \% / 1^{\circ} \mathrm{C}$ (at most), such that the observed artificial temperature increase results in a slight decrease in apparent resistivity. This temperature response corresponds to a value of $\pm 1.8 \% / \pm 10^{\circ} \mathrm{C}$ of the apparent resistivity change (Eqs. (1) and (3)). Although this estimate is equal to the observed temporal variations in impedance data (within one order of magnitude), both the polarity and the periods of time during which the peak variations of impedance occur (green curved lines in the 2nd and 4th plots from the top in Fig. 7) do not correlate well with the temperature monitoring curves (top in Fig. 7). Therefore, we conclude that such artifacts in the data, possibly relating to the effects of temperature change on the instruments, do not appear to have had significant effect on our data.

\subsection{Limitations of the 1-D inversion analysis}

In our 1-D inversion of subsurface resistivity structure, the largest uncertainties in the model arise due to the simple assumptions that must be made. The most significant issue in this regard is the assumption of a ' $1-\mathrm{D}$ ' structure. Figure 2 shows that our 1-D approximation breaks down in the deeper levels of the model (corresponding to the lowfrequency data in Fig. 2). Furthermore, the data recorded on the induction vector (Fig. 4) show that temporal resistivity changes can occur not just beneath the site, but farther from the site. To address these issues, multi-site MT monitoring (Peacock et al., 2012) and 3-D modeling are necessary, especially with regards to evaluating variations in resistivity structure at great depth.

Another important uncertainty arises from the inversion algorithm itself. Since we applied the Occam approach (Constable et al., 1987), the results we obtained (Figs. 6 and 8) represent the smoothest available model among all possible candidates. Note that either a sharp contrast in resistivity or a sharp change in resistivity can explain our data. For example, the real subsurface geological structure may comprise three layers (resistive-conductive-resistive) rather than the smooth structure portrayed in Fig. 6. In 


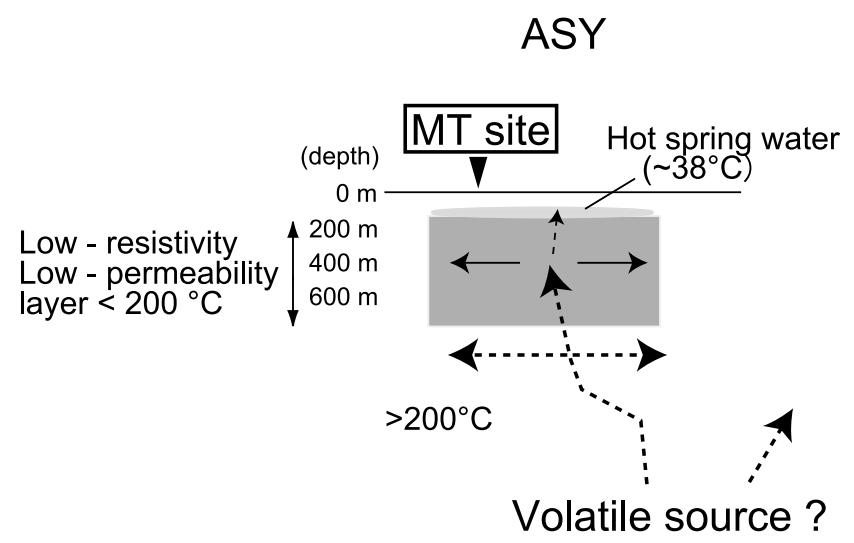

Fig. 10. Schematic view of interpretation of resistivity and temperature change. Mixing of deep volatile and shallow groundwater causes the resistivity change at shallow level. Dashed and solid arrows indicate rapid and slow fluid movement, respectively.

that particular case, the amplitude of the deduced temporal resistivity change may increase.

\section{Discussion}

\subsection{Interpretation of background resistivity structure}

Because the main characteristics of the inferred resistivity structure remained stable throughout the entire observation period (Fig. 9), it is possible to make meaningful geological interpretations of this resistivity structure. The inversion results (Figs. 6 and 9) reveal that at a depth of around $400 \mathrm{~m}$, a conductive layer appears to be sandwiched between two resistive layers. The sounding curves (Fig. 2) indicate that the conductive layer corresponds to impedance around $1 \mathrm{~Hz}$, where the apparent resistivity reaches a minimum. The resistivity of the conductive layer (a few ohm-m) is difficult to explain by the presence of water alone, as this would require an unrealistic porosity of greater than $30 \%$, as estimated from Archie's law and assuming that the resistivity of the water in this area is identical to that of seawater $(0.3 \mathrm{ohm}-\mathrm{m})$. This suggests that this area must contain a large amount of conductive clay minerals, such as smectite, and that these clays are contributing to the low resistivity of this particular layer. Indeed, the results of exploration drilling during geothermal energy exploration some $6 \mathrm{~km} \mathrm{SW}$ of our MT site (Uchida and Sasaki, 2006) identified a prominent smectite layer that causes a low-resistivity (conductive) zone beneath the Kirishima volcanoes. The fact that smectite breaks down at temperatures above $200^{\circ} \mathrm{C}$ (e.g., Ussher et al., 2000; Nurhasan et al., 2006; Uchida and Sasaki, 2006) means a high-temperature $\left(\sim 200^{\circ} \mathrm{C}\right)$ zone is likely to be present in the subsurface of the study area at a depth of $>1 \mathrm{~km}$, most probably beneath the MT site.

Conductive clay layers usually exhibit relatively low permeability (e.g., Jones and Dumas, 1993; Nurhasan et al., 2006; Aizawa et al., 2009a; Yamaya et al., 2009; Kanda et al., 2010). In particular, the top of such a clay layer can be sealed (i.e., impermeable), such that in the subsurface, any shallow, cold groundwater do not become wellmixed with deep, hot hydrothermal waters (Aizawa et al., 2009a). Although hot-spring waters are known to exist at a depth of $60 \mathrm{~m}$ near our MT site, the temperature of this water is actually quite low $\left(\sim 38^{\circ} \mathrm{C}\right)$, which provides one indication that the conductive layer that we modeled ap- pears to act as a low-permeability layer. Drilling log data, obtained from drilling some $400 \mathrm{~m}$ west of ASY in 1988, are available to a depth of $350 \mathrm{~m}$ (Kagiyama et al., 1994) and indicate that temperatures are highest $\left(60^{\circ} \mathrm{C}\right)$ at $100 \mathrm{~m}$ depth and gradually decrease to $36^{\circ} \mathrm{C}$ at a depth of $350 \mathrm{~m}$, suggesting that the shallow hot-spring water did not significantly mix with any deeper hydrothermal waters. However, since a prominent fumarolic area existed on Iwo-Yama volcano before 1990, high-permeability fracture zones may exist locally within this putative clayey low-permeability layer. Therefore, the relatively low temperature $\left(\sim 38^{\circ} \mathrm{C}\right)$ of the hot-spring waters at site ASY may be interpreted as evidence of the mixing of shallow, cold groundwater with small amounts of hot hydrothermal water originating from depth (Fig. 10).

\subsection{Resistivity changes}

Previous studies have shown that significant changes in subsurface resistivity may occur in association with large volcanic eruptions (Yukutake et al., 1990; Zlotnicki et al., 2003). In contrast, since the start of our monitoring study of temporal variations in subsurface resistivity structure and temperature, Shinmoe-dake volcano has gradually ceased activity and the observed MT impedance changes have only been very slight $( \pm 5 \%)$. However, based upon these data, we now suggest that significant changes in subsurface resistivity structure will occur prior to the next sub-Plinian eruption of this volcano. The geological scenario that we envisage is described as follows: 1) magma degassing occurs in association with the drop in pressure during ascent of the magma from deeper levels; 2) the resultant degassed volatiles reach shallow crustal levels faster than the ascending magma, to eventually become trapped near the surface by a shallow, low-permeability layer; (3) as a result, significant changes in resistivity structure occur in the subsurface (near the shallow conductive layer) before the next eruption ensues.

Although the above scenario may seem to be somewhat loosely constrained, there are two other independent studies that provide additional support for these hypotheses. The first arises from the fact that our MT site is located near Iwo-Yama volcano. Although fumaroles are not presently found at Iwo-Yama volcano, a fumarolic area existed there in 1990. At that time, ${ }^{3} \mathrm{He} /{ }^{4} \mathrm{He}$ ratios were determined for 
these fumarolic gases, yielding a value of $7.8 \mathrm{Ra}(1 \mathrm{Ra}$ corresponds to the atmospheric ${ }^{3} \mathrm{He} /{ }^{4} \mathrm{He}$ ratio), which demonstrates that magmatic gases were being supplied to the IwoYama fumaroles (Sato et al., 1999). In another study on Kirishima volcanic group (Aizawa et al., submitted), the 3D resistivity structure was modeled to a depth of $20 \mathrm{~km}$, indicating the presence of a sub-vertical conductive zone connecting a deep-seated conductive body (at a depth of $10 \mathrm{~km}$ ) to a shallow conductive layer near the Iwo-Yama volcano (Fig. 1). This structure seems to suggest the existence of a volcanic fluid pathway between a deep subsurface magma chamber and Iwo-Yama volcano. In summary, we suggest that our MT monitoring site is located where deepseated magmatic volatiles may be preferentially channeled to the surface.

The existence of such a volatiles pathway in the study area is also hinted at by the observed temporal variations in resistivity. Although the amplitudes are quite small, the resistivity changes recorded since March 2012 are the most remarkable in our data, both in terms of the observed MT impedance variations (Figs. 7-8) and the changes in inverted resistivity structure (Fig. 9). Notably, these changes appear to be synchronous with the temperature changes observed near the MT site (Fig. 9). In March of 2012, we observed concomitant temperature increases at two of the sites (ASY and SNY). At the ASY site, temperature was observed to gradually increase in March, lasting until late June. In contrast, at the SNY site, the temperature was suddenly observed to exceed the boiling point of water $\left(97^{\circ} \mathrm{C}\right.$ at the altitude of this site), and then gradually subside back to normal temperature levels. Significant rainfall was not observed at the time when these two temperature increases occurred at these sites. A more plausible interpretation of these observed temperature variations is that heat was transferred to these sites from deeper levels in the crust via volatiles. Faults and fracture networks are considered to be viable geological structures along which possible volatile pathways might occur in the subsurface (Uchida and Sasaki, 2006).

The MT inversion of the present study suggests that at shallow levels, resistivity structure changed at around March 2012, and accordingly, we interpret these changes in resistivity to be the result of the upward migration of volatiles, which may originated from magma degassing. For example, the $\pm 5 \%$ resistivity change in Fig. 8 can be explained by a coincident $\pm 2.5^{\circ} \mathrm{C}$ to $\pm 5^{\circ} \mathrm{C}$ temperature change (e.g., Ussher et al., 2000), which is within an order of magnitude of the observations made at SNY. Furthermore, degassed volatiles can supply ions to groundwater, thereby reducing its resistivity, meaning that the resistivity decrease at a depth of $0.4 \mathrm{~km}$ during March 2012 can quantitatively be explained by an increase in volatile supply to the groundwater in this area. However, it is difficult to explain the observed increase in resistivity during March 2012 at a depth of $0.1 \mathrm{~km}$; this depth roughly corresponds to the depth of low-temperature hot-spring waters in the site ASY area (Fig. 6). One possibility is that an increased supply of volatiles induced a widening of fractures in the low-permeability seal in this area, resulting in a depletion of shallow low-temperature groundwater. Alter- natively, an increase in gas bubbles within the groundwater in this area may have caused a significant increase in bulk resistivity (Wang et al., 2010).

Because the timing of onset of the observed temperature increases was similar between sites ASY and SNY, we suggest that the volatiles inferred to have been introduced to both of these regions simultaneously, might have originated from a single, deep-seated volatile source (Fig. 9). The observed difference in duration of these temperature increases is explained as follows. At site ASY, an underground hotspring exists at a depth of $60 \mathrm{~m}$, below which the lowpermeability clay layer exists, and we know that there are no fumaroles at the surface. Therefore, any volatiles present in that region are likely to be stored mostly at depth, and to have subsequently migrated gradually into shallow regions. In contrast, a high-temperature $\left(\sim 97^{\circ} \mathrm{C}\right)$ fumarolic zone exists at site SNY. Therefore, volatiles supplied to this site could escape to the surface, resulting in the observed sudden drop in the rate of temperature increase. Because the distance between the SNY and ASY sites is approximately 5 $\mathrm{km}$, their volatile source could be located at relatively deep levels in the crust.

\section{Conclusions}

We conducted a MT and temperature monitoring study in a region NW of Shinmoe-dake volcano. From these data, we have come to the following conclusions. 1) By 1-D inversion, we have successfully inferred that slight $( \pm 5 \%)$ temporal variations in resistivity structure took place during the observation period. 2) We observed simultaneous temporal changes in resistivity and temperature. These observations suggest that volatiles are occasionally re-supplied to the shallower parts of the subsurface near the MT monitoring site, which is situated $2 \mathrm{~km}$ from a region where ground deformation has been observed.

The limitations of this MT monitoring mostly arise from the fact that we were only able to deploy 1 station, and it seems clear from our data that the subsurface resistivity structure at this site becomes increasingly threedimensional at deeper levels. Furthermore, the temporal variations in MT response function suggest that resistivity changes may have occurred not only beneath the site, but also farther from the site. Ultimately, multi-site MT monitoring and the development of 3-D modeling in this area will be necessary to further explore the resistivity changes that take place in the future, especially at much deeper levels in the subsurface.

Acknowledgments. We thank A. Watanabe and J. Oikawa for maintenance of the MT site. The observations were conducted under the supervision of the Japan Meteorological Agency. We thank landowners and regional forest offices (Kagoshima and Miyazaki prefectures) for permitting the observations. The geomagnetic data used for the remote-reference processing were provided by the Kakioka Geomagnetic Observatory, Japan Meteorological Agency. Comments by M. Unsworth and an anonymous reviewer significantly improved the manuscript. Helpful reviews and constructive editing by C. Newhall, the guest editor of this special volume, are also greatly appreciated. This work was supported by a Grant-in-Aid from MEXT (KAKENHI No. 22900001, and the Multidisciplinary Research Project for High Strain Rate Zones). 


\section{References}

Aizawa, K., Y. Ogawa, and T. Ishido, Groundwater flow and hydrothermal systems within volcanic edifices: Delineation by electric self-potential and magnetotellurics, J. Geophys. Res.-Solid Earth, 114, B01208, doi:10.1029/2008jb005910, 2009a.

Aizawa, K., Y. Ogawa, M. Mishina, K. Takahashi, S. Nagaoka, N. Takagi, S. Sakanaka, and T. Miura, Structural controls on the 1998 volcanic unrest at Iwate volcano: Relationship between a shallow, electrically resistive body and the possible ascent route of magmatic fluid, J. Volcanol. Geotherm. Res., 187(1-2), 131-139, doi:10.1016/j.jvolgeores.2009.08.009, 2009b.

Aizawa, K., W. Kanda, Y. Ogawa, M. Iguchi, A. Yokoo, H. Yakiwara, and T. Sugano, Temporal changes in electrical resistivity at Sakurajima volcano from continuous magnetotelluric observations, J. Volcanol. Geotherm. Res., 199(1-2), 165-175, doi:10.1016/j.jvolgeores.2010.11.003, 2011.

Aizawa, K., T. Koyama, H. Hase, M. Uyeshima, W. Kanda, M. Utsugi, R. Yoshimura, Y. Yamaya, T. Hashimoto, K. Yamazaki, S. Komatsu, A. Watanabe, K. Miyakawa, and Y. Ogawa, Three dimensional resistivity structure and magma pluming system of Kirishima volcanoes as inferred from broad-band magnetotelluric data, J. Geophys. Res., (submitted).

Brenguier, F., N. M. Shapiro, M. Campillo, V. Ferrazzini, Z. Duputel, O. Coutant, and A. Nercessian, Towards forecasting volcanic eruptions using seismic noise, Nat. Geosci., 1(2), 126-130, doi:10.1038/ngeo104, 2008.

Chave, A. D. and D. J. Thomson, Bounded influence magnetotelluric response function estimation, Geophys. J. Int., 157(3), doi:10.1111/j.1365-246X.2004.02203.x, 2004.

Constable, S. C., R. L. Parker, and C. G. Constable, Occams inversion-a practical algorithm for generating smooth models from electromagnetic sounding data, Geophysics, 52(3), 289-300, doi:10.1190/1.1442303, 1987.

Gamble, T. D., J. Clarke, and W. M. Goubau, Magnetotellurics with a remote magnetic reference, Geophysics, 44(1), 53-68, 1979.

Hanekop, O. and F. Simpson, Error propagation in electromagnetic transfer functions: What role for the magnetotelluric method in detecting earthquake precursors?, Geophys. J. Int., 165, 763-774, doi:10.1111/j.1365246X.2006.02948.x., 2006

Hase, H., T. Hashimoto, S. Sakanaka, W. Kanda, and Y. Tanaka, Hydrothermal system beneath Aso volcano as inferred from self-potential mapping and resistivity structure, J. Volcanol. Geotherm. Res., 143(4), 259-277, doi:10.1016/j.jvolgeores.2004.12.005, 2005.

Jones, A. G. and I. Dumas, Electromagnetic images of a volcanic zone, Phys. Earth Planet. Inter, 81(1-4), 289-314, 1993.

Kagiyama, T., M. Yamaguchi, F. Masutani, and H. Utada, VLF, ELF-MT survey around Iwo-Yama, Kirishima volcanoes, Bull. Earthq. Res. Inst., 69, 211-239, 1994.

Kanda, W., M. Utsugi, Y. Tanaka, T. Hashimoto, I. Fujii, T. Hasenaka, and N. Shigeno, A heating process of Kuchi-erabujima volcano, Japan, as inferred from geomagnetic field variations and electrical structure, J. Volcanol. Geotherm. Res., 189(1-2), doi:10.1016/j.jvolgeores.2009.11.002, 2010.

Kappler, K. N., H. F. Morrison, and G. D. Egbert, Long-term monitoring of ULF electromagnetic fields at Parkfield, California, J. Geophys. Res., 115, B04406, doi:10.1029/2009jb006421, 2010.

Kozono, T., H. Ueda, T. Ozawa, T. Koyaguchi, E. Fujita, A. Tomiya, and Y. J. Suzuki, Magma discharge variations during the 2011 eruptions of Shinmoe-dake volcano, Japan, revealed by geodetic and satellite observations, Bull. Volcanol., 75, 695, doi:10.1007/s00445-013-0695-4, 2013.

Miller, V. and M. Savage, Changes in seismic anisotropy after volcanic eruptions: Evidence from Mount Ruapehu, Science, 293(5538), 22312233, 2001.

Nakada, S., M. Nagai, T. Kaneko, Y. Suzuki, and F. Maeno, The outline of the 2011 eruption at Shinmoe-dake (Kirishima), Japan, Earth Planets Space, 65, this issue, 475-488, doi:10.5047/eps.2013.03.016, 2013.

Nakao, S., Y. Morita, K. Goto, H. Yakiwara, S. Hirano, J. Oikawa, H. Ueda, T. Kozono, Y. Hirata, H. Takahashi, M. Ichiyanagi, Y. Ohta, T. Matsushima, and M. Iguchi, Crustal deformation before and after eruption on Jan. 26, 2011 in Kirishima Shinmoedake, Japan, Abstract 2011 Fall Meeting of the Volcanological Society of Japan, p. 27, 2011 (in Japanese)

Nakao, S., Y. Morita, K. Goto, H. Yakiwara, S. Hirano, J. Oikawa, H. Ueda, T. Kozono, Y. Hirata, H. Takahashi, M. Ichiyanagi, Y. Ohta, T. Matsushima, and M. Iguchi, Crustal deformation after the eruption on January, 2011 by continuous GPS observation in Kirishima Volcano,
Abstract 2012 JPGU meeting, 2012.

Nurhasan, Y. Ogawa, N. Ujihara, S. B. Tank, Y. Honkura, S. Onizawa, T. Mori, and M. Makino, Two electrical conductors beneath KusatsuShirane volcano, Japan, imaged by audiomagnetotellurics, and their implications for the hydrothermal system, Earth Planets Space, 58(8), 1053-1059, 2006

Ogawa, Y., N. Matsushima, H. Oshima, S. Takakura, M. Utsugi, K. Hirano, M. Igarashi, and T. Doi, A resistivity cross-section of Usu volcano, Hokkaido, Japan, by audiomagnetotelluric soundings, Earth Planets Space, 50(4), 339-346, 1998.

Ogawa, Y., M. Mishina, T. Goto, H. Satoh, N. Oshiman, T. Kasaya, Y. Takahashi, T. Nishitani, S. Sakanaka, M. Uyeshima, Y. Honkura, and M. Matsushima, Magnetotelluric imaging of fluids in intraplate earthquake zones, NE Japan back arc, Geophys. Res. Lett., 28(19), 3741-3744, 2001

Patane, D., G. Barberi, O. Cocina, P. De Gori, and C. Chiarabba, Timeresolved seismic tomography detects magma intrusions at Mount Etna, Science, 313(5788), 821-823, doi:10.1126/science.1127724, 2006.

Peacock, J. R., S. Thiel, P. Reid, and G. Heinson, Magnetotelluric monitoring of a fluid injection: Example from an enhanced geothermal system, Geophys. Res. Lett., 39, L18403, doi:10.1029/2012GL053080, 2012.

Sato, M., T. Mori, K. Notsu, and H. Wakita, Carbon and helium isotopic composition of fumarolic gases and hot spring gases from Kirishima volcanic area, Bull. Volcanol. Soc. Jpn., 44, 279-283, 1999.

Suzuki, Y., M. Nagai, F. Maeno, A. Yasuda, N. Hokanishi, T. Shimano, M. Ichihara, T. Kaneko, and S. Nakada, Precursory activity and evolution of the 2011 eruption of Shinmoe-dake in Kirishima volcanoinsights from ash samples, Earth Planets Space, 65, this issue, 591-607, doi:10.5047/eps.2013.02.004, 2013.

Uchida, T. and Y. Sasaki, Stable 3D inversion of MT data and its application to geothermal exploration, Explor. Geophys., 37, 223-230, 2006.

Ueda, H., T. Kozono, E. Fujita, Y. Kohno, M. Nagai, Y. Miyagi, and T. Tanada, Crustal deformation associated with the 2011 Shinmoe-dake eruption as observed by tiltmeters and GPS, Earth Planets Space, 65, this issue, 517-525, doi:10.5047/eps.2013.03.001, 2013.

Ussher, G., C. Harvey, R. Johnstone, and E. Anderson, Understanding the resistivities observed in Geothermal systems, Proceedings World Geothermal Congress, Kyushu, Japan, pp. 1915-1920, 2000.

Utada, H., Interpretation of time changes in the apparent resistivity observed prior to the 1986 eruption of Izu-Oshima volcano, Japan, J. Volcanol. Geotherm. Res., 126, 97-107, 2003.

Uyeshima, M., Y. Ogawa, Y. Honkura, S. Koyama, N. Ujihara, T. Mogi, Y. Yamaya, M. Harada, S. Yamaguchi, I. Shiozaki, T. Noguchi, Y. Kuwaba, Y. Tanaka, Y. Mochido, N. Manabe, M. Nishihara, M. Saka, and M. Serizawa, Resistivity imaging across the source region of the 2004 Mid-Niigata Prefecture earthquake (M6.8), central Japan, Earth Planets Space, 57(5), 441-446, 2005.

Wang, S., M. Lee, M. K. Park, and J.-M. Kim, Box experiments on monitoring the $\mathrm{CO} 2$ migration in a homogeneous medium using electrical resistivity survey, Geosci. J., 14(1), doi:10.1007/s12303-010-0009-1, 2010

Yamaya, Y., T. Mogi, T. Hashimoto, and H. Ichihara, Hydrothermal system beneath the crater of Tarumai volcano, Japan: 3-D resistivity structure revealed using audio-magnetotellurics and induction vector, J. Volcanol. Geotherm. Res., 187, 193-202, doi:10.1016/j.jvolgeores.2009.09.008, 2009.

Yamazaki, K., M. Teraishi, K. Ishihara, S. Komatsu, and K. Kato, Subtle changes 1 in strain prior to sub-Plinian eruptions recorded by vault-housed extensometers during the 2011 activity at Shinmoe-dake, Kirishima volcano, Japan, Earth Planets Space, (submitted).

Yoshimura, R. et al., Magnetotelluric transect across the Niigata-Kobe Tectonic Zone, central Japan: A clear correlation between strain accumulation and resistivity structure, Geophys. Res. Lett., 36, L20311, doi:10.1029/2009g1040016, 2009.

Yukutake, T., T. Yoshino, H. Utada, H. Watanabe, Y. Hamano, and T. Shimomura, Changes in the electrical resistivity of the central cone, Mihara-yama, of Oshima volcano observed by a direct current method, J. Geomag. Geoelctr., 42, 151-168, 1990.

Zlotnicki, J., Y. Sasai, P. Yvetot, Y. Nishida, M. Uyeshima, F. Fauquet, H Utada, H. Takahashi, and G. Donnadieu, Resistivity and self-potential changes associated with volcanic activity: The July 8, 2000 Miyakejima eruption (Japan), Earth Planet. Sci. Lett., 205, 139-154, 2003.

K. Aizawa (e-mail: aizawa@sevo.kyushu-u.ac.jp), T. Koyama, M. Uyeshima, H. Hase, T. Hashimoto, W. Kanda, R. Yoshimura, M. Utsugi, Y. Ogawa, and K. Yamazaki 